ISSN: 1858-4837; E-ISSN: 2598-019X

Volume 16, Nomor 2 (2021),

https://jurnal.uns.ac.id/region

DOI: 10.20961/region.v16i2.39852

\title{
Faktor-Faktor yang mempengaruhi partisipasi masyarakat dalam perencanaan tata ruang Kota Bukittinggi
}

\author{
Factors that influence citizen's participation in spatial planning in Bukittinggi \\ City
}

\author{
L S Dewi ${ }^{1}$, F Tan ${ }^{1}$, M Nazer ${ }^{1}$ \\ ${ }^{1}$ Program Studi Perencanaan Pembangunan, Fakultas Ekonomi Universitas Andalas
}

Corresponding author's email: liza.sandra81@gmail.com

\begin{abstract}
Abstrak. Perencanaan tata ruang kota merupakan suatu proses sosial, yang tidak hanya berfokus kepada pembangunan fisik saja, tapi harus melibatkan manusia yang terdapat didalamnya yang berhak mendapatkan kesempatan untuk mendapatkan kehidupan yang lebih baik. Masyarakat merupakan komponen yang secara langsung dipengaruhi dan berpengaruh terhadap rencana tata ruang. Keterlibatan masyarakat dalam proses penyusunan RTRW merupakan salah satu cara untuk menghindari adanya penolakan-penolakan di kemudian hari. Seperti halnya yang terjadi di Kota Bukittinggi, penolakan terhadap dokumen RTRW Kota Bukittinggi Nomor 6 Tahun 2011, dimana masyarakat menuntut peninjauan ulang atas Ruang Terbuka Hijau yang secara massive ditetapkan di dua keluarahan agar diubah kembali menjadi kawasan budidaya (perumahan dan pertanian lahan kering). Penolakan tersebut merupakan gambaran rendahnya partisipasi masyarakat dalam penyusunan dokumen RTRW. Hal tersebut bisa dipengaruhi oleh beberapa fakor, terutama faktor internal yang berasal dari diri masyarakat itu sendiri. Tujuan dari penelitian ini adalah untuk menganalisis faktorfaktor yang mempengaruhi tingkat partisipasi masyarakat di Kota Bukittinggi. Penelitian ini menggunakan data primer dengan menyebar kuesioner kepada masyarakat yang terlibat langsung dalam proses penyusunan RTRW. Analisis yang digunakan adalah analisis kuantitatif dengan menggunakan regresi logistik. Hasil penelitian yang mempengaruhi partisipasi masyarakat di Kota Bukittinggi adalah jenis kelamin, usia dan pendapatan.
\end{abstract}

Kata Kunci: Partisipasi Masyarakat; Perencanaan Partisipatif; Tata Ruang

Received: February 11, 2020; Accepted: July 14, 2020 Available online: July 15, 2021

Copyright $\odot$ 2021, REGION: Jurnal Pembangunan Wilayah dan Perencanaan Partisipatif 


\begin{abstract}
Spatial planning is a social process, which does not only focus on physical development, but also have to concern about the citizens, who deserve the chance to get a better life. Citizens are the component that are directly affected and influenced by the spatial planning. Citizen's Participation is one way to avoid future rejections. For instance the case of Bukittinggi, there was a public rejection to the Bukittinggi's spatial document No 6 year 2011, where citizens demanded a review of the Green Open Space which was massively determined in two sub-district to be converted back into a cultivation (housing and agriculture). The rejection is the picture of the low participation on spatial planning. This can be influenced by several factors, especially internal factors. The purpose of this study is to analyse the factors that influence the level of citizen participation in Bukittinggi City.. This study used primary data by distributing questionnaires to citizens who directly involved in the spatial planning process. The method used a quantitative analysis using logistic regression. The results of the research show that the factors that influence citizen participation in Bukittinggi City are gender, age, and income.
\end{abstract}

Keywords: Citizen Participation; Participatory Planning; Spatial Planning

\title{
1. Pendahuluan
}

Kota adalah kawasan yang cenderung mengalami perkembangan pesat dari tahun ke tahun. Hal ini dengan sendirinya mendorong perkembangan pemanfaatan ruang yang perlu ditanggapi secara arif. Perkembangan fisik kawasan di kota mengarah pada fungsi kota itu sendiri yang tercermin pada kehidupan ekonomi dan sosio politik pada sifat-sifat fisik dan tata ruangnya [1]. Dapat diartikan, terjadi perkembangan kota menyebabkan terjadinya pergeseran fungsi ruang.

Perencanaan tata ruang kota merupakan suatu proses sosial, yang tidak hanya berfokus kepada pembangunan fisik saja, tetapi harus melibatkan manusia yang terdapat di dalamnya yang berhak mendapatkan kesempatan untuk mendapatkan kehidupan yang lebih baik. Masyarakat merupakan komponen yang secara langsung terpengaruhi dan berpengaruh terhadap dokumen RTRW. Keterlibatan masyarakat merupakan hal yang sangat penting dalam proses penyusunan RTRW.

Mengesampingkan peran masyarakat dalam pengelolaan suatu wilayah merupakan pemicu permasalahan ke depannya. Masalah akan menjadi semakin kompleks karena masyarakat sekarang merupakan masyarakat yang cerdas (knowledge based society) dengan banyak tuntutan. Mereka menjadi lebih kritis terhadap kebijakan-kebijakan yang diambil oleh pemerintah. Munculnya berbagai permasalahan dalam tata ruang merupakan implikasi dari tidak dilibatkannya masyarakat secara aktif dalam penyusunan tata ruang tersebut. Peran serta atau partisipasi masyarakat berperan penting dalam menentukan kesesuaian tata ruang dalam pembangunan kota kedepannya dan tentunya kebutuhan masyarakat itu sendiri.

Setelah memasuki era desentralisasi, Indonesia mulai bergerak ke arah perencanaan partisipatif. Tapi dari beberapa penelitian yang dilakukan, tingkat partisipasi masyarakat 
masih bergerak di level tokenisme. Hal ini masih jauh dari kondisi partisipasi maksimal yang diharapkan seperti yang diamanatkan dalam PP Nomor 68 Tahun 2010 mengenai bentuk dan tata cara peran masyarakat dalam penataan ruang. Seperti penelitian yang dilakukan oleh Saputra [2] tentang partisipasi masyarakat dalam penyusunan Rencana Tata Ruang dan Wilayah Kabupaten Bulungan, dimana partisipasi yang dijalankan masih jauh dari pedoman tata cara peran masyarakat dalam penataan ruang yang diatur dalam Peraturan Pemerintah Nomor 68 Tahun 2010, dalam pengambilan keputusan hanya diwakili oleh elite pemerintah saja, sehingga sulit untuk menentukan apakah hasil yang dicapai sudah berdasarkan keinginan masyarakat.

Bukittinggi merupakan kota nomor dua terbesar di Sumatera Barat yang merupakan pusat perdagangan dan pariwisata. Penetapan Bukittinggi sebagai Pusat Kegiatan Wilayah menjadikan posisi Bukittinggi sangat penting dalam tata ruang Propinsi Sumatera Barat (Perda Propinsi Sumatera Barat Nomor 13 Tahun 2012) [3], yang berarti menjadi simpul kedua di Sumatera Barat setelah Padang sebagai Pusat Kegiatan Nasional, dan juga sebagai pusat perdagangan dan jasa yang melayani kabupaten/kota di sekitarnya. Dengan posisi strategis di antara jalur lintas Sumatera Medan, Palembang, Padang dan berada di antara jalur PadangPekanbaru menjadikan Bukittinggi berkembang menjadi pusat perekonomian.

Bukittinggi semakin berkembang dan bergerak maju, yang akhirnya menjadi salah satu penyebab terjadinya pergeseran fungsi ruang menyesuaikan dengan dinamika perkembangannya. Hal ini harus bisa ditampung dalam sebuah perencanaan tata ruang yang fleksibel. Perencanaan kota sebagai suatu proses sosial yang melibatkan manusia sebagai komponen utamanya sangat terlihat dalam perkembangan RTRW Kota Bukittinggi.

Perencanaan kota sebagai suatu proses sosial yang melibatkan manusia sebagai komponen utamanya sangat terlihat dalam perkembangan RTRW Kota Bukittinggi. Penolakan terhadap Perda RTRW Nomor 6 Tahun 2011 merupakan satu contoh terpinggirkannya aspirasi masyarakat. Dalam Perda Nomor 6 Tahun 2011, ruang terbuka hijau (RTH) secara massive ditetapkan di dua kelurahan, yaitu Kelurahan Puhun Pintu Kabun dan Bukit Apit. Dimana sebagai penetralisir polusi dan paru-paru kota, RTH seharusnya menyebar di seluruh kelurahan. Penetapan kawasan RTH yang terpusat hanya di dua kelurahan ini juga menghambat terjadinya pembangunan di kedua kawasan tersebut sehinga memicu tuntutan masyarakat di kedua kelurahan tersebut agar fungsi kawasan RTH dapat ditinjau kembali menjadi kawasan budidaya (perumahan dan pertanian lahan kering).

Masih rendahnya tingkat partisipasi ini dipengaruhi oleh beberapa faktor yang menjadi pendorong masyarakat untuk berperan aktif dalam penyusunan RTRW yaitu faktor internal dan eksternal. Faktor internal merupakan faktor yang berasal dari dari dalam diri masyarakat sendiri, sedangkan faktor eksternal adalah semua faktor yang mempengaruhi masyarkat untuk ikut berpartisipasi meliputi semua pihak yang berkepentingan dan mempunyai pengaruh terhadap program kecuali masyarakat [4]. Faktor-faktor eksternal tersebut adalah peran pemerintah dalam pembinaan dan pemberian informasi kepada masyarakat, peranan 
konsultan perencana, dan peranan pihak swasta (Pengembang, LSM). Secara lebih khusus artikel ini hanya akan membahas mengenai faktor-faktor internal yang mempengaruhi partisipasi masyarakat dalam penyusunan revisi RTRW Kota Bukittinggi Tahun 2017.

\section{Metode}

Penghitungan regresi ditujukan untuk mengetahui pengaruh fungsional antara variabel jenis kelamin, usia, pendidikan, pekerjaan, dan penghasilan masyarakat. Analisis ini menggunakan analisis logistic regresion model untuk menunjukkan probabilitas seseorang dalam ikut berpartisipasi dalam penyusunan revisi RTRW Kota Bukittinggi. Probabilitas ini didasarkan pada asumsi mengenai variabel random yang diteliti berbentuk logistic distribution function model. Analisis ini digunakan karena kuesioner yang digunakan berupa data dikotomik/biner dengan variabel bebas berskala interval/kategorik [5].

Teknik pengambilan sampel dalam penelitian ini adalah pengambilan sampel non acak (non probality sampling) yaitu purposive sampling atau sampling dengan maksud tertentu [6]. Dengan teknik ini tidak semua subjek penelitian memiliki peluang yang sama untuk dipilih sebagai sampel, karena dalam pelaksanaannya digunakan pertimbangan tertentu [7]. Dalam penelitian ini sampel yang diambil adalah wakil-wakil masyarakat yang terlibat langsung dalam penyusunan RTRW Kota Bukittinggi, yaitu sebanyak 127 orang.

Model transformasi logit yang digunakan untuk mengestimasi faktor-faktor yang mempengaruhi partisipasi masyarakat dalam penyusunan revisi RTRW Kota Bukittinggi tahun 2017 yaitu dengan memodifikasi model persamaan sehingga menjadi:

$$
\begin{aligned}
z(x)= & \beta_{0}+\beta_{1} J E N I S \_K E L A M I N+\beta_{2} U S I A+\beta_{3} \text { PENDIDIKAN }+\beta_{4} \text { PEKERJAAN } \\
& +\beta_{5} \text { PENGHASILAN }+\varepsilon i
\end{aligned}
$$

Dimana

$\beta o=$ Konstanta

$\varepsilon i=$ Kesalahan pengganggu

\subsection{Variabel}

Model transformasi logit yang digunakan dibangun dari beberapa variabel bebas dan variabel terikat seperti yang dijelaskan pada Tabel 1. Data-data dari variabel ini diambil dengan cara penyebaran kuesioner berupa kuesioner tertutup dengan jenis data kategorik dimana responden diminta memilih salah satu pilihan dari dua pilihan jawaban yang disediakan.

Tabel 1. Keterangan variabel bebas dan variabel terikat.

\begin{tabular}{cccc}
\hline No. & \multicolumn{1}{c}{ Ket. Variabel } & \multicolumn{1}{c}{ Value label } & Jenis data \\
\hline 1 & Y $=$ Partisipasi Masyarakat & $1=$ berpartisipasi \\
& Kota Bukittinggi & $0=$ Tidak berpartisipasi & Kategorik \\
2 & X1 = Jenis Kelamin & $1=$ Laki-laki & Kategorik \\
\hline
\end{tabular}




\begin{tabular}{|c|c|c|c|}
\hline No. & Ket. Variabel & Value label & Jenis data \\
\hline & & 0 =perempuan & \\
\hline 3 & $\mathrm{X} 2$ = Usia & $\begin{array}{l}1=>50 \text { tahun } \\
0=\leq 50 \text { tahun }\end{array}$ & Kategorik \\
\hline 4 & X3 = Pendidikan & $\begin{array}{l}1=\text { Perguruan Tinggi } \\
0=\text { Sekolah Menengah Kebawah }\end{array}$ & Kategorik \\
\hline 5 & X3 =Pekerjaan & $\begin{array}{l}1=\text { Perdagangan } / \text { Jasa } \\
0=\text { Non Perdagangan } / \text { Jasa }\end{array}$ & Kategorik \\
\hline 6 & X4 =Penghasilan & $\begin{array}{l}1=>U M K \\
0=\leq U M K\end{array}$ & Kategorik \\
\hline
\end{tabular}

Faktor internal merupakan faktor yang berasal dari diri individu itu sendiri. Di antara faktor internal yang mempengaruhi partisipasi masyarakat adalah jenis kelamin, usia, tingkat pendidikan, tingkat pendapatan, dan pekerjaan [8].

2.1.1. Jenis kelamin. Jenis kelamin atau gender membawa makna perbedaan peran, fungsi, status dan tanggungjawab antara laki-laki dan perempuan yang merupakan hasil dari konstruksi budaya yang dilanjutkan dari satu generasi ke generasi berikutnya [9]. Perbedaan konsep mengenai gender ini melahirkan perbedaan peran dan tanggungjawab laki-laki dan perempuan dalam masyarakat.

2.1.2. Usia. Perbedaan usia memberi pengaruh terhadap keaktifan masyarakat dalam berpartisipasi. Adanya senioritas akan memunculkan dua golongan yang berbeda dalam berbagai hal, seperti dalam menyampaikan pendapatan dan pengambilan keputusan, yaitu golongan muda dan tua [10].

2.1.3. Tingkat Pendidikan. Litwin menyatakan karakteristik masyarakat dalam pembangunan partisipatif adalah tingkat pengetahuan masyarakat tentang usaha-usaha partisipasi yang diberikan masyarakat dalam pembangunan. Tingkat pengetahuan ini akan berbanding lurus dengan tingkat pendidikan yang dimiliki oleh masyarakat tersebut [11].

2.1.4. Penghasilan. Tingkat penghasilan akan mempengaruhi terhadap waktu luang yang bisa dialokasikan untuk berpartisipasi. Menurut Barros penduduk yang lebih kaya kebanyakan membayar pengeluaran tunai dan jarang melakukan kerja fisik sendiri. Sementara penduduk yang berpenghasilan pas-pasan akan cenderung berpartisipasi dalam hal tenaga [12].

2.1.5. Pekerjaan. Pekerjaan secara langsung akan berpengaruh kepada tingkat penghasilan seseorang, yang secara tidak langsung akan mempengaruhi waktu luang seseorang dalam berpartisipasi, misalnya dalam hal menghadiri pertemuan [4].

\subsection{Tahapan pengujian}

Dalam pengujian model dilakukan beberapa tahapan pengujian sebagai berikut: 


\subsubsection{Likelihood ratio test}

Untuk mengetahui peran seluruh variabel penjelas di dalam model secara bersama-sama, dapat digunakan uji likelihood ratio atau uji signifikansi model. Pengujian ini dilakukan dengan membandingkan nilai observasi terhadap nilai dugaannya yang diperoleh pada model yang terbentuk dengan model penuh. Untuk menentukan kelayakan model digunakan statistik uji nisbah kemungkinan (likelihood ratio test), yaitu statistik uji G dengan persamaan [13]:

$$
\mathrm{G}=-2 \ln \left(\frac{\text { likelihood tanpa variabel penjelas }}{\text { likelihood dengan variabel penjelas }}\right)=-2 \ln \left(\frac{\mathrm{L}_{0}}{\mathrm{~L}_{\mathrm{k}}}\right)
$$

Hipotesis yang digunakan dalam pengujian ini adalah:

$\mathrm{HO}: \beta 1=\beta 1=\ldots . .=\beta \mathrm{k}=0$ (tidak ada pengaruh seluruh variabel independen terhadap variabel dependen)

$\mathrm{H} 1$ : paling tidak terdapat satu $\beta \mathrm{j} \neq 0$ untuk $\mathrm{j}=1,2,3, \ldots, \mathrm{k}$ (ada pengaruh variabel independen terhadap variabel dependen)

Statistik uji G mengikuti distribusi Khi-Kuadrat dengan derajat bebas sehingga hipotesis ditolak jika $\mathrm{G}>\chi^{2}[\alpha,(r-1)(k-1)]$ atau $p$-value $<\alpha$.

2.2.2. Uji wald. Selain pengujian parameter secara keseluruhan, juga harus dilakukan pengujian koefisien secara individual [13]. Hipotesis yang digunakan dalam pengujian secara individual adalah:

$\mathrm{HO}: \beta \mathrm{j}=0$ (tidak ada pengaruh seluruh variabel independen terhadap variabel dependen)

$\mathrm{H} 1: \beta \mathrm{j} \neq 0$ untuk $\mathrm{j}=1,2,3, \ldots, \mathrm{k}$

Statistik uji yang digunakan menurut Gujarati [13] adalah:

$$
\mathrm{W}=\left(\frac{\beta_{\mathrm{j}}}{\operatorname{Se}\left(\beta_{\mathrm{j}}\right)}\right)^{2}
$$

Dimana,

$\beta \mathrm{j}=$ Koefisien regresi

$\operatorname{Se} \beta \mathbf{j}=$ Standard Error $\beta \mathbf{j}$

Hipotesis ditolak jika $W>\chi^{2}[\alpha,(r-1)(k-1)]$ atau $p$-value $<\alpha$

2.2.3. Odds ratio. Nilai odds ratio merupakan besaran yang digunakan untuk melihat perbandingan masing-masing kategori dari variabel bebas dalam menerangkan peubah tak bebas. Nilai ini diperoleh dengan mengeksponensialkan koefisien dari peubah dalam model regresi logistik yang terbentuk. Dengan kata lain, odds ratio merupakan perbandingan tingkat resiko antara 2 nilai peubah bebas, misalnya $\mathrm{x}=1$ dan $\mathrm{x}=0$, maka rumus untuk mencari odds ratio adalah sebagai berikut (Gujarati, 1993):

$$
\begin{aligned}
& \theta=\exp \left(\beta_{\mathrm{i}} \mathrm{x}\right) \\
& \theta=\text { odds ratio } \\
& \beta i=\text { koefisien logistik variable ke-i }
\end{aligned}
$$




\section{Hasil penelitian dan pembahasan}

Perencanaan merupakan suatu proses, prosedur, dan metode dalam mencapai tujuan, mengidentifikasi dan menilai pilihan-pilihan yang tersedia, serta pengembangan strategi dalam mencapai pilihan-pilihan tersebut. Ini merupakan aktivitas yang diakukan manusia dalam mengambil keputusan yang beorietasi masa depan [14]. Friedman dalam bukunya Planning in the Public Domain menyatakan bahwa perencanaan adalah bagaimana menghubungkan antara pengetahuan teknis menjadi public actions [15].

Partisipasi merupakan keterlibatan secara sukarela oleh masyarakat dalam menciptakan perubahan dan pengambilan keputusan. Seseorang akan terdorong untuk berpartisipasi jika ia bisa menemukan dirinya merupakan bagian dari sebuah komunitas yang bertanggung jawab terhadap komunitasnya itu sendiri. Cornwall menyatakan partisipasi tidak hanya sebagai kebutuhan dasar, tapi merupakan bagian dari hak asasi manusia [16]. Masyarakat berhak untuk ikut berpartisipasi aktif dalam perencanaan yang mempengaruhi langsung terhadap kehidupan mereka.

Partisipasi masyarakat adalah suatu proses berbasis komunitas, dimana masyarakat mempengaruhi proses pengambilan keputusan yang dimulai dari level terendah (bottom up). Mereka akan merasa lebih terdorong untuk ikut berpartisipasi jika permasalahan atau perencanaan yang dirancang berhubungan secara langsung dengan kehidupan mereka. Partisipasi ini hanya akan terjadi jika semua stakeholder bekerja sama dalam menerapkan perubahan yang mempengaruhi keputusan [17]. Jadi dalam hal ini sangat dibutuhkan komitmen yang sama di antara semua stakeholder dalam mewujudkan partisipasi yang baik sehingga dapat menghasilkan perencanaan yang bisa menampung aspirasi masyarakat.

Paul merumuskan partisipasi merupakan suatu proses aktif masyarakat dalam mempengaruhi arah pelaksanaan suatu kegiatan atau program dengan maksud meningkatkan kesejahteraan masyakat dalam hal pendapatan, pertumbuhan, kemandirian, dan nilai-nilai yang mereka hargai [18]. Oakley juga mengutip pendapat Cohen dan Uphoff bahwa partisipasi merupakan keterlibatan masyarakat dalam proses pengambilan keputusan, dalam pelaksanaan program, pemanfaatan program, dan pembangunan, serta keterlibatan mereka dalam mengevaluasi program tersebut [19].

Perencanaan partisipatif adalah bentuk spesifik dari kegiatan perencanaan yang dilakukan oleh otoritas publik terutama di tingkat lokal yang memungkinkan warga untuk terlibat dalam proses perencanaan [17]. Fokus utama perencanaan partisipatif bukanlah dalam menghasilkan suatu rencana, tapi menciptakan dialog antara berbagai pihak yang mempunya berbagai macam harapan dan persepsi mengenai isu dan permasalahan yang sedang dibahas. Perencanaan partisipatif merupakan proses sosial dimana masyarakat perlu ikut serta untuk memudahkan analisis tentang persoalan masyarakat dalam mencapai prioritas berdasarkan kesepakatan bersama. 
Dalam Undang-Undang Nomor 26 Tahun 2007 tentang Penataan Ruang telah dijelaskan secara rinci mengenai partisipasi masyarakat dalam penataan ruang, yaitu:

1. Penyelenggaraan penataan ruang dilakukan oleh pemerintah dengan melibatkan peran serta masyarakat,

2. Peran masyarakat dalam penataan ruang sebagaimana dimaksud pada ayat (1) dilakukan antara lain, melalui:

a. Partisipasi dalam penyusunan rencana tata ruang;

b. Partisipasi dalam pemanfaatan tara ruang; dan

c. Partisipasi dalam pengendalian pemanfaatan tata ruang.

Dari pengujian statistik, analisis regresi logistik digunakan untuk menguji pengaruh variabel penelitian yang menjadi pendorong terhadap partisipasi masyarakat di dalam penyusunan revisi RTRW Kota Bukittinggi. Sebelum output diinterpretasikan terlebih dahulu dilakukan pengujian, di antaranya pengujian secara keseluruhan (overall fit test), pengujian secara parsial (partial test), dan uji kecocokan model (goodness of fit).

\subsection{Pengujian secara keseluruhan (overall fit test)}

Pengujian ini bertujuan untuk melihat paling tidak satu variabel bebas signifikan mempengaruhi variabel terikat. Pengujian ini dapat dilihat dalam tabel Omnibus Test of Model Coefficients dari data primer dengan menggunakan Program SPSS versi 16, sebagai berikut (lihat Tabel 2):

Tabel 2. Hasil uji overall fit test model analisis faktor-faktor yang mempengaruhi partisipasi masyakat dalam penyusunan revisi RTRW

Kota Bukittinggi tahun 2017.

\begin{tabular}{lllll}
\hline \multicolumn{5}{c}{ Omnibus Tests of Model Coefficients } \\
& Chi-square & df & Sig. \\
\hline Step 1 & Step & 61.739 & 5 & .000 \\
& Block & 61.739 & 5 & .000 \\
& Model & 61.739 & 5 & .000 \\
\hline
\end{tabular}

Dalam menentukan kelayakan model, digunakan statistik uji nisbah kemungkinan (likelihood ratio test), yaitu statistik uji $\mathrm{G}$. Hipotesis yang digunakan dalam pengujian ini adalah:

HO : $\beta 1=\beta 1=\ldots . .=\beta k=0$ (tidak ada pengaruh seluruh variabel independen terhadap variabel dependen)

$\mathrm{H} 1$ : paling tidak terdapat satu $\beta \mathrm{j} \neq 0$ untuk $\mathrm{j}=1,2,3, \ldots, \mathrm{k}$ (ada pengaruh variabel independen terhadap variabel dependen)

Tolak HO jika nilai sig $<0.05$.

Dari output omnibus test terlihat bahwa signifikansi model $0.000<0.05$ yang berarti secara umum model signifikan secara statistik. Keputusan: Tolak HO.

Terlihat nilai G2 sebesar 61.739 dengan $p$-value 0.000 (model) yang berarti dengan tingkat kepercayaan $95 \%$ ada minimal satu variabel bebas yang berpengaruh pada variabel terikat. 
Sehingga dapat disimpulkan bahwa model layak dan dapat digunakan untuk analisis lebih lanjut.

\subsection{Uji parsial (partial test)}

Pengujian ini bertujuan untuk melihat variabel-variabel bebas yang signifikan mempengaruhi variabel terikat secara parsial, yang dapat dilihat dalam Tabel 3 di bawah. Nilai yang digunakan berdasarkan Wald statistik atau ditunjukkan dengan nilai signifikan kurang dari 0,05 untuk tingkat kepercayaan $95 \%$ ( $\alpha=5 \%$ ). Variabel yang nilai signifikannya kurang dari 0,05 merupakan variabel yang signifikan secara parsial.

Tabel 3. Hasil regresi logistik pengujian signifikan faktor-faktor yang mempengaruhi partisipasi masyakat dalam penyusunan revisi RTRW Kota Bukittinggi tahun 2017.

\begin{tabular}{cccccccc}
\hline & \multicolumn{7}{c}{ Variables in the Equation } \\
& B & S.E. & Wald & df & Sig. & Odds Ratio \\
\hline \multirow{4}{*}{ Step 1 } & X1_JenisKelamin(1) & -2.521 & .695 & 13.163 & 1 & .000 & .080 \\
& X2_usia(1) & -2.005 & .644 & 9.709 & 1 & .002 & .135 \\
& X3_pendidikan(1) & .069 & .592 & .014 & 1 & .907 & 1.072 \\
& X4_pekerjaan(1) & .448 & .603 & .552 & 1 & .457 & 1.565 \\
& X5_Gaji(1) & -2.255 & .752 & 8.984 & 1 & .003 & .105 \\
& Constant & 2.238 & .575 & 15.129 & 1 & .000 & 9.376 \\
\hline
\end{tabular}

a. Variable(s) entered on step 1: X1_JenisKelamin, X2_usia, X3_pendidikan, X4_pekerjaan, X5._Gaji.

Berdasarkan tabel di atas menunjukkan bahwa dengan tingkat kepercayaan 95\% ( $\alpha=0.05)$ variabel jenis kelamin, usia, dan pendapatan signifikan mempengaruhi partisipasi masyarakat dalam penyusunan revisi RTRW Kota Bukittinggi tahun 2017.

\subsection{Uji kecocokan model (goodness of fit)}

Pengujian ini digunakan untuk melihat apakah model cocok dengan data dalam keterkaitannya antar variabel. Uji hipotesis untuk kecocokan model adalah sebagai berikut: $\mathrm{HO}$ : Model telah cukup mampu menjelaskan data/sesuai

$\mathrm{H} 1$ : Model tidak cukup mampu menjelaskan data

Tolak HO jika signifikansi value Chi-Square uji Hosmer and Lemeshow $<0.05$.

Tabel 4. Uji kecocokan model (goodness of fit).

\begin{tabular}{cccc}
\hline \multicolumn{2}{c}{ Hosmer and Lemeshow Test } \\
Step & Chi-square & df & Sig. \\
\hline 1 & 3.433 & 6 & .753 \\
\hline
\end{tabular}

Dari Tabel 4 terlihat significant value adalah $0.753>0.05$, keputusannya adalah terima H0. Dengan tingkat keyakinan 95\%, dapat diyakini bahwa model regresi logistik yang digunakan telah cukup mampu menjelaskan kecocokan data, dengan kata lain model ini layak dipakai untuk analisis selanjutnya karena tidak ada perbedaan yang nyata antara klasifikasi yang diprediksi dengan klasifikasi yang diamati. 


\subsection{Output classification model}

Classification model digunakan untuk menentukan kesesuaian model dalam memprediksi partisipasi masyarakat di Kota Bukittinggi. Semakin tinggi nilai overall percentage (mendekati 100) maka ketepatan model dalam memprediksi akan semakin baik. Dari Tabel 5 terlihat bahwa nilai overall percentage sebesar $84,3 \%$. Ini menunjukkan bahwa kemampuan model secara keseluruhan dalam menebak kondisi yang terjadi adalah $84.3 \%$. Dengan kata lain, model memiliki kemampuan yang cukup baik dalam memprediksi dan layak untuk digunakan.

Tabel 5. Output classification model analisis partisipasi masyarakat dalam penyusunan revisi RTRW Kota Bukittinggi 2017.

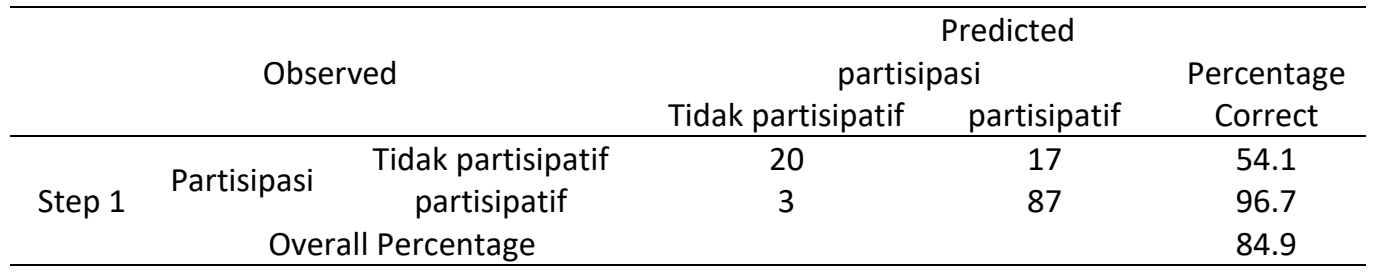

\subsection{Output hasil uji parameter model}

Penelitian ini bertujuan untuk melihat pengaruh variabel bebas (jenis kelamin, usia, pendidikan, pekerjaan, dan gaji) terhadap variabel terikat (partisipasi masyarakat). Untuk signifikansi parameter (koefisien $\beta$ ) secara parsial dapat dilihat dengan nilai $p$ value pada kolom Sig. pada Tabel 6 di bawah. Jika nilai $p$ value $<0,05$ maka parameter berarti signifikan.

Tabel 6. Hasil estimasi koefisien model, nilai uji wald, signifikansi, dan nilai odds ratio dari regresi logistik model analisis partisipasi masyarakat dalam penyusunan revisi RTRW Kota Bukittinggi 2017.

\begin{tabular}{cccccccc}
\hline \multicolumn{7}{c}{ Variables in the Equation } \\
& B & S.E. & Wald & df & Sig. & Odds Ratio \\
\hline \multirow{4}{*}{ Step 1 } & X1_JenisKelamin(1) & -2.521 & .695 & 13.163 & 1 & .000 & .080 \\
& X2_usia(1) & -2.005 & .644 & 9.709 & 1 & .002 & .135 \\
& X3_pendidikan(1) & .069 & .592 & .014 & 1 & .907 & 1.072 \\
& X4_pekerjaan(1) & .448 & .603 & .552 & 1 & .457 & 1.565 \\
& X5_Gaji(1) & -2.255 & .752 & 8.984 & 1 & .003 & .105 \\
& Constant & 2.238 & .575 & 15.129 & 1 & .000 & 9.376 \\
\hline
\end{tabular}

a. Variable(s) entered on step 1: X1_JenisKelamin, X2_usia, X3_pendidikan, X4_pekerjaan, X5._Gaji.

Dari Tabel 6 dapat dilihat pada kolom sig, dari 5 parameter yang diuji, terdapat 3 (tiga) parameter yang mempunyai nilai signifikan kecil dari 0.05 yaitu jenis kelamin, usia, dan gaji. Hasil output model regresi logistik partisipasi masyarakat dalam penyusunan revisi RTRW Kota Bukittinggi 2017 dapat ditulis dalam bentuk sebagai berikut:

$$
\mathrm{z}(\mathrm{x})=2.238-2.521 \mathrm{X} 1-2.005 \mathrm{X} 2+0.069 \mathrm{X} 3+0.448 \mathrm{X} 4-2.255 \mathrm{X} 5
$$

Model di atas menunjukkan bahwa konstanta bernilai positif, 2.238 yang bisa diartikan jika semua variabel bebas bernilai 0 (nol) maka peluang masyarakat untuk berpartisipasi adalah 


$$
\begin{gathered}
\ln \left[\frac{\mathrm{P}}{1-\mathrm{P}}\right]=2,238 \text {, atau } \\
\mathrm{P}=\left[\frac{\mathrm{e}^{2,238}}{1+\mathrm{e}^{1,335}}\right]=\frac{9,3745634}{10,3745634}=0,9036
\end{gathered}
$$

Model regresi logistik menghasilkan model dengan koefisien beta yang diinterpretasikan melalui odds ratio. Dari tabel di atas terdapat 3 (tiga) variabel yang mempengaruhi partisipasi masyarakat dengan tingkat kepercayaan $5 \%$, yaitu jenis kelamin, usia, dan gaji.

Jenis kelamin responden berpengaruh terhadap partisipasi dengan nilai signifikan $0.000<0.05$ pada taraf nyata $5 \%$. Dari tabel terlihat nilai odds ratio adalah 0.080 yang dapat diartikan peluang laki-laki untuk berpartisipasi cenderung lebih besar 0.080 kali dari wanita. Puspitawati menyatakan gender merupakan hasil kesepakatan antara manusia dan bukan bersifat kodrati, sehingga bisa saja bervariasi di setiap daerah, tergantung dengan waktu dan budaya setempat [9]. Hal ini sejalan dengan hasil dari penelitian ini, dimana sebagian besar responden yang berpartisipasi adalah tokoh masyarakat dan ninik mamak Kota Bukittinggi yang didominasi oleh laki-laki. Bukittinggi merupakan kota yang masih menjunjung tinggi tatanan adat, terutamanya tatanan adat kurai $\mathrm{V}$ jorong. Dimana dalam tatanan adat ini kelompok laki-laki yang bertindak sebagai mamak, mempunyai tugas mengawasi dan melakukan kontrol terhadap garis keturunan keluarganya [20]. Laki-laki masih memiliki peranan penting dalam penentuan dan pengambilan keputusan yang menyangkut dengan anak kemenakannya. Sebagian kecil wanita yang terlibat dalam partisipasi merupakan tokoh masyarakat, bundo kanduang, dan kader-kader kelurahan.

Rendahnya partisipasi wanita dalam proses partisipatif juga dijelaskan oleh [21] karena beberapa kendala:

1. Secara psikologis wanita terbiasa menjadi bagian masyarakat yang terpinggirkan, sehingga kesadaran untuk ikut serta dalam proses partisipatif tidak maksimal.

2. Hal ini juga dipengaruhi oleh warisan konsep top down, sehingga wanita belum siap menjadi subjek sebagai penentu arah pembangunan lingkungannya.

3. Sebagian besar wanita masih belum berani untuk tampil ke depan dan mengemukakan pendapatnya, sehingga posisi mereka seringkali sebagai pihak yang hanya menyetujui perencanaan yang dikemukakan laki-laki.

Untuk usia juga memiliki pengaruh terhadap partisipasi dengan nilai signifikan sebesar 0.002 $<0.05$ pada taraf $5 \%$, dengan nilai odds ratio 0.135 , dimana disini dapat dilihat masyarakat dengan usia lebih dari 50 tahun, memiliki peluang 0.135 kali lebih besar untuk berpartisipasi dibandingkan dengan masyarakat berusia kurang dari 50 tahun. Hal ini menggambarkan adanya unsur senioritas dalam partisipasi. Dimana usia akan mempengaruhi keaktifan seseorang dalam berpartisipasi, golongan yang lebih tua masih dianggap sebagai golongan yang lebih berpengalaman dan akan lebih didengar pendapatnya dalam mengambil keputusan [8]. 
Sementara itu untuk pendapatan mempengaruhi partisipasi dengan nilai signifikan $0.003<$ 0.05 pada taraf nyata $5 \%$, dengan nilai odds ratio 0.105 , yang dapat diartikan bahwa peluang masyarakat yang memiliki pendapatan diatas UMK Kota Bukittinggi adalah 0.105 kali lebih besar untuk berpartisipasi dibandingkan dengan masyarakat yang memiliki gaji dibawah UMK. Semakin besar penghasilan seseorang maka akan mempengaruhi peluang seseorang untuk ikut berpartisipasi. Tingkat penghasilan yang mencukupi akan mempengaruhi seberapa besar waktu luang yang bisa mereka alokasikan untuk kegiatan partisipasi, tanpa harus disibukkan dengan kegiatan dalam mencari tambahan penghasilan lainnya.

\section{Kesimpulan}

Rendahnya tingkat partisipasi di Indonesia secara umum dan Kota Bukittinggi secara khusus dipengaruhi oleh beberapa faktor internal yang bersumber dari diri masyarakat sendiri. Di antara faktor internal yang berpengaruh adalah jenis kelamin, usia, dan pendapatan. Sebagai masyarakat yang masih memegang teguh tatanan adat yang kental, peran laki-laki sebagai penanggung jawab dalam tatanan keluarga masih mempunyai peran dominan dalam partisipasi di Kota Bukittinggi. Begitu juga dengan usia, prinsip senioritas masih melekat dalam kehidupan bermasyarakat, sehingga partisipasi lebih didominasi golongan yang lebih tua yang dianggap lebih berpengalaman. Pendapatan pun akan mempengaruhi waktu luang seseorang untuk aktif berpartisipasi. Dimana semakin besar pendapatan seseorang maka semakin besar peluang mereka untuk aktif berpartisipasi.

\section{Referensi}

[1] Melville CB. Perencanaan Kota Komprehensif: Pengantar dan Penjelasan. Yogyakarta: Gadjah Mada University Press; 1995.

[2] Saputra A. Partisipasi Masyarakat dalam Penyusunan Rencana Tata Ruang dan Wilayah Kabupaten Bulungan 2017.

[3] Republik Indonesia. Peraturan Daerah Propinsi Sumatera Barat Nomor 13 Tahun 2012 tentang Rencana Tata Ruang Wilayah Provinsi Sumatera Barat Tahun 2012-2032. Sumatra Barat: 2012.

[4] Suciati. Partisipasi Masyarakat Dalam Penyusunan Rencana Umum Tata Ruang Kota Pati. Tesis 2006.

[5] Hosmer, Lemeshow. Applied Logistic Regression New York. Wiley: 1989.

[6] C N, Achmadi. Metodologi Penelitian. Jakarta: Bumi Aksara; 2003.

[7] Sevilla C.G et al. Pengantar Metode PenelitianTerjemahan Alimuddin Tuwu. Jakarta: Universitas Indonesia; 1993.

[8] Slamet Y. Pembangunan Masyarakat Berwawasan Partisipasi. Surakarta: Sebelas Maret University Pers; 1993.

[9] Puspitawati H. Gender dan keluarga: konsep dan realita di Indonesia. PT IPB Press 2012. https://doi.org/10.1017/S0033583501003705.

[10] Soedarno P et al. Ilmu Sosial Dasar: Buku Panduan Mahasiswa. Jakarta: PT. Gramedia Pustaka Utama; 1992.

[11] Litwin H. Correlates of Community Collaboration. In Yair Levy and Howard Letwin (Eds) Community and Cooperative In Participatory Development. England: Gower 
Publishing Company; 1986.

[12] A B. Perencanaan Daerah Partisipatif (Yogyakarta: Pembaruan). 1993.

[13] Gujarati D. Ekonometrika Dasar. Jakarta: Erlangga; 1993.

[14] Elliott M, Planning R, Tech G. History and Theories of Planning Why do we do what we do ? Relationship between History and Theory in Planning Planning : 2014.

[15] Friedman J. Planning in The Public Domain (From Knowledge to Action). Princeton: Princeton University Pers; 1987.

[16] Cornwall A. Beneficiary consumer citizen: perspectives on participation for poverty reduction. Sida Stud 2000:91.

[17] 4 Council of Europe Conference of Ministers responsible for Spatial / Regional Planning. A Handbook On Territorial Democracy and Public Participation in Spatial Planning (Greek Presidency of CEMAT). Europe: 2014.

[18] Paul S. Community Participation in Development Projects, World Bank Discussion Paper. 2015.

[19] Oakley P. The Concept Of Participation in Development. Landscape and Urban Planning. Elsevier Sci Publ BV Amsterdam 1991;20:115-22.

[20] Firman F. "Adat Basandi Syarak, Syarak Basandi Kitabullah." 2010/01/06 2010:54-5.

[21] Rinawati R. PARTISIPASI WANITA DALAM PEMBANGUNAN (Kajian Gender mengenai Partisipasi Wanita dalam Pembangunan Partisipatif melalui Pemberdayaan Masyarakat). Mimbar 2004;XX:387-405.

[22] Republik Indonesia. Peraturan Daerah Kota Bukittinggi Nomor 6 Tahun 2011 Tentang Rencana Tata Ruang dan Wilayah Kota Bukittinggi 2010-2030. Kota Bukittinggi: 2011.

[23] Republic H. on Territorial Democracy and Public Participation on Territorial Democracy and Public Participation 2014.

[24] Republik Indonesia. Peraturan Daerah Kota Bukittinggi Nomor 11 Tahun 2017 Tentang Perubahan Atas Peraturan Daerah Nomor 6 Tahun 2011 Tentang Rencana Tata Ruang dan Wilayah Kota Bukittinggi 2010-2030. Kota Bukittinggi: 2017. 